\title{
Environmental impacts associated with the production, use, and end-of-life of a woollen garment
}

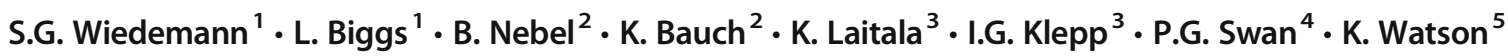

Received: 3 May 2019 / Accepted: 5 May 2020 / Published online: 25 May 2020

(C) The Author(s) 2020

\begin{abstract}
Purpose The textiles industry is a substantial contributor to environmental impacts through the production, processing, use, and end-of-life of garments. Wool is a high value, natural, and renewable fibre that is used to produce a wide range of garments, from active leisure wear to formal wear, and represents a small segment of the global fashion industry. Woollen garments are produced by long, global value chains extending from the production of 'greasy' wool on sheep farms, through processing to garment make-up, retail, consumer use, and end-of-life. To date, there have been limited life cycle assessment (LCA) studies on the environmental impacts of the full supply chain or use phase of garments, with the majority of wool LCA studies focusing on a segment of the supply chain. This study aimed to address this knowledge gap via a cradle-to-grave LCA of a woollen garment. Methods This study investigated greenhouse gas (GHG) emissions, fossil fuel energy, and water stress associated with the production, use, and end-of-life of a lightweight woollen sweater (300-g wool), together with inventory results for freshwater consumption and land occupation. Primary datasets were used for the wool production and wool processing stages, while primary datasets relating to consumer garment use were supplemented with literature data. Impacts were calculated and reported per garment wear event.

Results and discussion Impacts per wear were $0.17( \pm 0.02) \mathrm{kg} \mathrm{CO}_{2}$-e GHG, $0.88( \pm 0.18) \mathrm{MJ}$ fossil energy, and $0.96( \pm 0.42)$ $\mathrm{H}_{2} \mathrm{O}$-e water stress. Fossil fuel energy was dominated by wool processing, with substantial contributions of energy also arising from retail and garment care. Greenhouse gas emissions from wool production (farming) contributed the highest proportion of impacts, followed by lower contributions from processing and garment care. Contributions to water stress varied less across the supply chain, with major contributions arising from production, processing, and garment use.

Conclusions Opportunities to improve the efficiency of production, processing, and garment care exist, which could also reduce resource use and impacts from wool. However, the number of garment wear events and length of garment lifetime was found to be the most influential factor in determining garment impacts. This indicated that consumers have the largest capacity to influence the sustainability of their woollen garments by maximising the active garment lifespan which will reduce overall impacts.
\end{abstract}

Keywords Wool $\cdot$ Apparel $\cdot$ Textiles $\cdot$ GHG $\cdot$ Water $\cdot$ Energy $\cdot$ LCA $\cdot$ Sweater

Communicated by: Yi Yang

Electronic supplementary material The online version of this article (https://doi.org/10.1007/s11367-020-01766-0) contains supplementary material, which is available to authorized users.

S.G. Wiedemann

stephen.wiedemann@integrityag.net.au

1 Integrity Ag and Environment, Toowoomba, QLD, Australia

2 thinkstep, Wellington, New Zealand

3 Consumption Research Norway (SIFO), Oslo Metropolitan University, Oslo, Norway

4 Paul G. Swan and Associates Pty. Ltd., Sydney, Australia

5 NSWWater, Buronga, NSW, Australia

\section{Introduction}

The global textile industry is known to generate substantial environmental impacts from the production of raw materials, fibre and garment manufacturing, and garment use phases (Claudio, 2007; Muthu, 2014). In the past 15 years, clothing manufacturing doubled (Remy et al. 2016) mainly related to the expansion of synthetic fibre production. During the same period, the global population only rose by $20 \%$ (UN, 2019), indicating that garment utilisation has also decreased. This has resulted in higher demands on global resources and higher environmental impacts from raw material production and clothing manufacturing. Considering these higher environmental impacts, improvements in environmental efficiency 
are required. This will need to be achieved by changes in textile production systems and in the way consumers use and care for their garments. To quantify, understand, and reduce these environmental impacts, the life cycle assessment (LCA) method, a robust, well-established and effective tool, determines the full supply chain impacts and reporting these relative to the final product (Finnveden et al., 2009). The present study applied the LCA approach to assess the environmental impacts of woollen garments.

In the textile sector, wool is a niche product consisting of approximately $1.2 \%$ of the market share of the global textile market (IWTO, 2018). However, wool is nonetheless used to produce a wide range of garments, from active leisure wear to formal wear. Wool fabrics have insulative and odour-resistant properties (e.g. Johnson et al., 2003; Laing, 2019) that improve garment functionality and reduce the need for washing (Laitala et al. 2018). Typically, woollen garments are also kept for longer periods of time than garments of other fibre types (Laitala et al. 2018), suggesting that this fibre may provide opportunities for reducing environmental impacts by extending the active life of the garment.

The wool value chain is long and complex: extending from the production of 'greasy' wool on farm, through a series of distinct processing stages, to garment make-up, retail, and consumer use. While wool is produced in a large number of countries, fine apparel wool is predominantly produced from Merino sheep in the Southern Hemisphere in Australia, South Africa, New Zealand, and South America (Petrie, 1995). As with most textiles, wool processing predominantly occurs in China and India, with a smaller proportion occurring in Europe (IWTO, 2018). The major markets for woollen garments are western Europe, China, and the USA (Swan, 2010).

To date, published wool LCA studies have investigated the farm stage (Wiedemann et al., 2016; Brock et al., 2013) and the early stages of wool processing (Brent and Hietkamp, 2003). Assessment tools such as the Sustainable Apparel Coalition's Material Sustainability Index (SAC MSI - SAC, 2017) report impacts for wool fabric production using a life cycle approach, but use proxy inventory data to estimate impacts from spinning, dyeing, knitting (or weaving), and finishing, and report impacts only to the point of fabric production. In many studies, the use phase represents a major impact area for at least one impact category (Muthu, 2015), and this area remains a significant knowledge gap in understanding impacts from woollen garments. There are also important differences when assessing a partial or full life cycle with respect to reference flows and functional units (FU).

While partial LCA's can provide valuable information on individual phases and components of a product life cycle, without a full life cycle understanding of impacts, it is difficult to identify the highest priorities to improve environmental efficiency, and there is a risk of burdenshifting between value chain stages when recommending improvements. Moreover, the important role of consumers in defining the length of garment lifetime (i.e. the time a garment stays in active use) has not been assessed for woollen garments resulting in an important knowledge gap in this area.

While cradle-to-gate LCAs may report impacts per kilogramme of fibre or fabric, cradle-to-grave LCAs assess the function of a garment, which is multi-faceted. Guidelines for defining the FU of a system propose answering four questions: 'What?', 'How much?', 'How well?', and 'For how long?' (EC-JRC, 2010). There are no previous studies on woollen sweaters that answer these four questions for defining the FU.

In response to these knowledge gaps, the present study aimed to (i) investigate environmental impacts and resource use hotspots across the full cradle-to-grave value chain for a woollen garment and (ii) to investigate the effect of garment wears and the resulting garment lifetime on the environmental impacts of woollen garments using survey data, providing a science-based definition of the FU of a woollen garment.

\section{Materials and methods}

\subsection{Goal and scope}

This study investigated impacts associated with using a woollen sweater, including all stages of the value chain, from wool production to garment disposal (Fig. 1). The study applied an attributional (aLCA) approach consistent with ISO 14044 (ISO, 2006), ISO 14046 (ISO, 2014), and the wool LCA guidelines developed by IWTO (2016).

\subsubsection{Functional unit}

Impacts were reported for a functional unit (FU) of one garment, used for a single wear event (i.e. one garment). For clarity, results for the total life of the garment are reported in the supplementary materials.

The garment was a unisex, lightweight woollen sweater (pullover) containing $300 \mathrm{~g}$ of fine Merino wool (fibre diameter $<20 \mu \mathrm{m}$ ). Because of the inherent properties of wool, the garment is breathable and odour repellent. This type of garment is considered suitable for casual and formal social occasions (i.e. at school and work) and can be worn as a mid-layer or outer-layer garment.

One garment wear included an average of 0.2 washing and drying cycles and was $0.92 \%$ of the total life of the garment (i.e. the full garment life was 109 wears). A detailed explanation of all data and assumptions relating to the $\mathrm{FU}$ is provided in Section 2.2.3. 


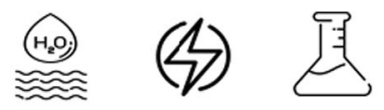

Process inputs including electricity, fuels, water, chemicals (detergents, dyes etc.)
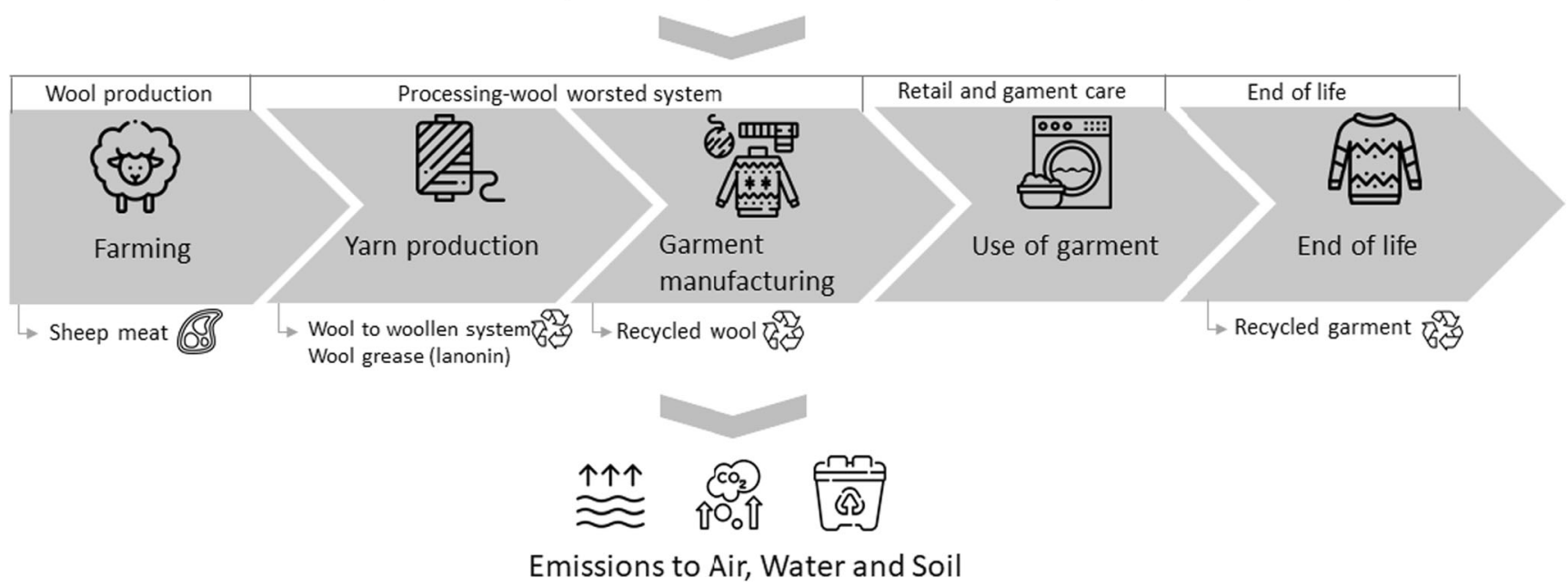

Fig. 1 Wool life cycle from cradle to grave showing major production stages and co-products

\subsubsection{Impact assessment}

This impact assessment included global warming, water stress, and aggregated inventory results for fossil fuel energy use, freshwater consumption, and land occupation calculated using methods described below. The available datasets and impact assessment methods were insufficient to enable assessment of a wider range of impact categories, though it is noted that other impacts, including chemical toxicity and eutrophication, may be relevant for the woollen garment life cycle and these require further investigation in the future.

Fossil fuel energy Modelling of fossil fuel use was based on the inventory of purchased goods, services, and transport distances throughout the value chain and was reported in megajoules (MJ) with lower heating values (LHVs). Impacts generated in the manufacture of purchased inputs were modelled using background data sourced from the 'ecoinvent 3.5' database (ecoinvent, 2019) and where relevant, from countryspecific databases (i.e. the AustLCI database - ALCAS, 2017; and the U.S. LCI database - NREL, 2012). Where impacts from background processes were substantial, these background processes were reviewed to harmonise allocation choices and system boundaries to the maximum extent possible.

Freshwater consumption and stress-weighted water use Freshwater consumption refers to evaporative losses, incorporation of water into products, or water that is withdrawn and subsequently not released back into the same river catchment or is released into the ocean (ISO 2014). The focus on freshwater consumption reflects the intent of LCA to investigate the impacts of resource use either on human health, natural ecosystems, or competitive water users (Bayart et al., 2010). The water inventory covered all sources and losses associated with wool production, processing, and garment care, both in the foreground and background systems, using a water balance approach to determine consumptive losses throughout the value chain.

Stress-weighted water use was assessed using the water stress index (WSI) of Pfister et al. (2009) and reported in water equivalents $\left(\mathrm{H}_{2} \mathrm{O}-\mathrm{e}\right)$ after Ridoutt and Pfister (2010). Regional specific water flows throughout the inventory were categorised according to the appropriate characterisation factors based on the WSI values from Pfister et al. (2009). The WSI indicates the portion of freshwater consumption that deprives other users, e.g. downstream human users and ecosystems, and is thus a measure of the scarcity of freshwater.

Greenhouse gas emissions and global warming Greenhouse gas emissions were calculated throughout the value chain from the fossil fuel inventory (described in Section 2.1.2), and via direct modelling of impacts from livestock emissions, using methods described in Wiedemann et al. (2016) and the Australian National Inventory Report (Commonwealth of Australia, 2018). As recommended by ISO/TS 14067 (ISO, 2013), GHG emissions arising from land use (LU), including change to soil carbon stocks, and direct land-use change (dLUC), including changes to vegetation carbon stocks, were considered using the analysis of Wiedemann et al. (2016), but were reported separately. Short-term biogenic carbon fluxes that did not contribute to stock changes in atmospheric carbon dioxide were excluded.

The impact assessment used AR5 100-year global warming potential $\left(\mathrm{GWP}_{100}\right)$ values (IPCC, 2013). For comparison, a 
sensitivity analysis was also conducted using 100-year global temperature potential $\left(\mathrm{GTP}_{100}\right)$ values. GTP is an end-point metric, which aims to report the impact on temperature at a point in the future. This provides a revised equivalency for short-term gases such as methane and therefore provided additional information for wool systems.

Land occupation Land occupation was determined using a disaggregated land inventory accounting for differences in land type using four categories: (i) occupation of non-arable (rangelands) for pasture, (ii) occupation of cropland cultivated for grain or forage crop production, (iii) occupation of arable land for pasture, and (iv) industrial land occupation. The proportion of land in each category was determined from the inventories presented in Wiedemann et al. (2016) and from the wool processing inventories. Land occupation was reported in $\mathrm{m}^{2}$ year ${ }^{-1}$.

\subsection{Inventory data}

\subsubsection{Wool production}

Inventory data were sourced from Wiedemann et al. (2016), which was the most recent and comprehensive dataset available for this Merino wool type. Datasets represented a survey of 52 farms in two regions in Australia, averaged over a 5-year period to remove the impact of seasonal variation. The two regions selected were the tablelands region of New South Wales (NSW) and the south-eastern region of Western Australia (WA), which both produce a high proportion of fine Merino wool of under $20 \mu \mathrm{m}$ diameter, suited to producing the garment under investigation. For the purposes of the analysis, each selected region supplied equal amounts of wool, and the attributes of the Merino wool production system and inventory data are provided in Table 1. Transport of greasy wool (i.e. wool prior to scouring) from farms to wool scouring assumed transportation of wool bales with an average mass of $178 \mathrm{~kg}$ (AWEX, 2014), using 1.5-kg nylon packs (AWEX, 2013). They were initially moved by road (38-t load, truck) from the farm to the nearest auction and port location, then via transoceanic freight by container ship travelling a normal trade route from Australia to China. Greasy wool was then transported by road transportation (30-t load, truck) from the port in China to mills for processing.

\subsubsection{Processing inventory}

The sweater was produced using ring-spun yarns typical of the 'worsted' wool processing system, which produces finer yarns and garments with a smoother finish when compared with those produced by the shorter fibre 'woollen' system.
Inventory data from each stage of wool processing was obtained from a survey of large wool processors $(n=15)$ located in China and India, processing the equivalent of $\sim 15 \%$ of gross Australian wool production annually.

The typical processes required for the manufacture of a machine-washable Merino sweater are scouring, top making, shrink proofing, top dyeing, spinning, knitting, finishing, and garment make-up (Wood, 2010). These processes are described in detail in the supplementary materials and additional data are provided for chemical use and wastewater treatment (Table S1, Table S2).

Inventory data were analysed and validated by comparison with previous case studies (thinkstep, 2017) and any anomalies were reviewed and corrected in consultation with an expert group (Roy Kettlewell and Rajesh Bahl, pers. comm.). Industry data were predominantly collected for the years 2016 and 2017, with the exception of data collected during a previous study (Henry et al., 2015). Weighted averages were calculated based on the amount of wool processed by each facility. Inventory processes were modelled in sequence, but to protect the confidentiality, data were amalgamated for all processes from wool scouring to garment make-up (see data in Table 2). The impact of capital infrastructure and machinery was excluded from foreground processes on account of the very small contribution from these inputs and the long timeframe which this equipment is used for.

Transportation from the finishing plant to the use phase regions was assumed to be by a transoceanic freight ship travelling a normal trade route from China to the port of Rotterdam in the Netherlands. Garments were then assumed to be transported by road (truck) to retail locations throughout Europe.

\subsubsection{Use phase retail and garment care inventory}

The use phase included retail, consumer transport associated with garment purchase, and garment care by the consumer. Inventory methods are outlined in the following sections and inventory data are reported in Table 3 and additional detail is provided in the supplementary materials (Table S3 to Table S12).

Water inventory data associated with garment care utilised the ecoinvent European (excluding Switzerland) tap water process. Wastewater flows from domestic garment washing were modelled using ecoinvent European municipal wastewater treatment processes.

Retail and consumer transport Garment retail impacts and consumer transport associated with garment purchase was modelled using inventory data from ecoinvent (2019). Impacts from retail were modelled as follows. The annual energy usage per square metre in European fashion shops was assumed to be $350 \mathrm{kWh}$ (CIBSE, 2012), which was 
Table 1 Farm and flock characteristics, inputs, flows, and outputs for the regional average farms based on primary and modelled data in the eastern High Rainfall Zone and the western Wheat Sheep Zone of Australia. Data sourced from Wiedemann et al. (2016)

\begin{tabular}{|c|c|c|c|}
\hline Category & Parameter and units & NSW $(n=34)$ & WA $(n=18)$ \\
\hline Pasture land utilised for sheep & $\mathrm{Ha}$ & 647 & 1367 \\
\hline On-farm crop land utilised for sheep & $\mathrm{Ha}$ & 0 & 74 \\
\hline \multirow[t]{3}{*}{ Energy } & Electricity $\left(\mathrm{kWh}\right.$ year $^{-1}$ ) & 7162 & 3769 \\
\hline & Diesel $\left(\mathrm{L}_{\text {year }}{ }^{-1}\right)$ & 2747 & 5714 \\
\hline & Petrol $\left(\mathrm{L}_{\text {year }}{ }^{-1}\right)$ & 2106 & 2218 \\
\hline Water & Drinking water including losses (ML year ${ }^{-1}$ ) & 6.1 & 15.4 \\
\hline \multirow[t]{2}{*}{ Fertiliser and soil conditioner } & Superphosphate $\left(\mathrm{t}_{\text {year }}{ }^{-1}\right)$ & 19 & 62 \\
\hline & Lime $\left(t_{\text {year }}{ }^{-1}\right)$ & 3 & 44 \\
\hline Purchased feed & Protein grains $\left(\mathrm{t}\right.$ year $\left.{ }^{-1}\right)$ & 36 & 54 \\
\hline \multirow[t]{2}{*}{ Chemicals } & Veterinary products ( $\$$ expenditure year ${ }^{-1}$ ) & 8651 & 8424 \\
\hline & Herbicides $\left(\$\right.$ expenditure year $\left.{ }^{-1}\right)$ & 391 & 2926 \\
\hline \multirow[t]{2}{*}{ Overheads } & Administration (\$ expenditure year ${ }^{-1}$ ) & 4579 & 6238 \\
\hline & Transport of farm inputs (t km) & 2649 & 12,543 \\
\hline \multirow[t]{6}{*}{ Sheep flock characteristics } & Breeding ewes (no. joined) & 1516 & 2179 \\
\hline & Total number of adult sheep & 3074 & 3837 \\
\hline & Reproduction rate (\% lambs to ewes joined) & 84.6 & 76.2 \\
\hline & Flock feed intake (t DMI) & 1049.4 & 1264.6 \\
\hline & Annual sheep sales (total kg LW) & 52,173 & 65,677 \\
\hline & Annual wool clip (total kg greasy) & 12,454 & 18,106 \\
\hline Biophysical allocation $^{\mathrm{a}}$ & Allocation to wool (\%) & 46.0 & 48.5 \\
\hline
\end{tabular}

${ }^{a}$ Biophysical allocation updated to reflect revised protein yields for wool and live weight. DMI, dry matter intake

attributed to garments based on the total retail sales per square metre, reported by NEXT (NEXT PLC, 2015). A more detailed explanation of this calculation is provided in the supplementary material. The UK has the second largest retail volume in Europe (GfK, 2012), and as such, this calculation was assumed to be reasonably representative of fashion retail in Europe. Sweaters were assumed to be sold without packaging.

Consumer transport was assumed to include cars and trains in equal proportions using ecoinvent processes, with an assumed $25-\mathrm{km}$ round trip for each garment purchased. The wool garment was attributed $25 \%$ transport impacts, assuming other purchases were also made.

Length of use phase The use phase was defined as the total number of times a garment was worn by a first and subsequent user. The average number of lifetime wears for the first user of 79 wears (average of male and female users) was sourced from a survey of consumers (survey methods and results outlined in the supplementary materials). Lifetime wears is a highly uncertain result because of varied consumer behaviour, with responses ranging from 0 to more than 500 wears. After ownership by the first user, garments were either disposed of to municipal waste, recycled, given to family members, or donated to charity and re-sold. The second use phase (reuse) was treated as an extension in the number of lifetime wears, with a single washing process included between the first and second user. The rate of garments donated for reuse was $76.1 \%$ from the consumer survey data. This was higher than the $47.6 \%$ reuse rate reported by WRAP (2011) for t-shirts, but was considered more representative of the particular garment investigated. Greenhouse gas emissions and fossil fuel inventory data were included, based on WRAP (2011) for the collection, sorting, and site operation activities required for woollen sweater reuse in the UK.

It was assumed that the second use phase $\left(\mathrm{L}_{2}\right)$ was half the length of the first $\left(L_{1}\right)$, i.e. 39.5 wears, though no surveys were found in the literature that separately reported the duration of use for a reused garment and there remains some uncertainty about these factors. Accounting for the garment reuse rate $\left(\mathrm{R}_{\mathrm{r}}\right)$ observed in the consumer survey $(76.1 \%)$, the total active length of the use phase (U) was 109 wears, as calculated in Eq. 1 below.

$\frac{U=\left(L_{1}+\left(L_{2} \times R_{r}\right)\right)}{U=(79.0+(39.5 \times 0.76))=109.0}$

It was observed in the survey data that garment use reported by males and females was different (128 and 93 wears, 
Table 2 Major wool processing inputs, flows and outputs (excl. process chemicals ${ }^{\mathrm{a}}$ ) for wool processing plants surveyed in China and India

\begin{tabular}{|c|c|c|c|c|}
\hline & Material/process & Unit & Amount & Uncertainty (\%) \\
\hline \multirow[t]{15}{*}{ Input } & Greasy wool & $\mathrm{kg}$ & 1885.1 & \pm 8 \\
\hline & Water, China wool processing, WSI region 0.6255 & $\mathrm{k} \mathrm{L}$ & 219.3 & \pm 15 \\
\hline & Electricity, high voltage (China) & $\mathrm{kWh}$ & $12,539.6$ & \pm 51 \\
\hline & Process steam & $\mathrm{kg}$ & 9547.1 & \pm 60 \\
\hline & Diesel & $\mathrm{kg}$ & 13.3 & \pm 33 \\
\hline & Petrol, unleaded & $\mathrm{kg}$ & 8.0 & \pm 6 \\
\hline & LPG & $\mathrm{kg}$ & 0.7 & \\
\hline & Light fuel oil & $\mathrm{kg}$ & 1.7 & \\
\hline & Coal, combusted in industrial boiler & $\mathrm{kg}$ & 0.3 & \pm 93 \\
\hline & Packaging, LDPE, film & $\mathrm{kg}$ & 15.0 & \pm 24 \\
\hline & Packaging, other & $\mathrm{kg}$ & 64.3 & \pm 12 \\
\hline & Transport, transoceanic freight ship Australia to China & $\mathrm{t} \mathrm{km}$ & $16,080.4$ & \\
\hline & Transport, articulated truck - processing to port and port to retail & $\mathrm{t} \mathrm{km}$ & 1569.7 & \\
\hline & Transport, truck, long haul (38 t)—farm to port & $\mathrm{t} \mathrm{km}$ & 1131.0 & \\
\hline & Land occupation, industrial area & $\mathrm{m}^{2} \mathrm{a}$ & 0.003 & \\
\hline \multirow[t]{4}{*}{ Product } & Final garment & $\mathrm{kg}$ & 1000.0 & \\
\hline & Wool grease & $\mathrm{kg}$ & 109.1 & \pm 66 \\
\hline & Wool, transferred to woollen system ${ }^{\mathrm{b}}$ & $\mathrm{kg}$ & 249.1 & \pm 17 \\
\hline & Wool, transferred to recycling & $\mathrm{kg}$ & 50.0 & \pm 2 \\
\hline \multirow[t]{5}{*}{ Waste } & Water, to wastewater treatment plant & $\mathrm{k} 1$ & 186.2 & \pm 26 \\
\hline & Water, emissions to air & $\mathrm{k} 1$ & 33.0 & \pm 42 \\
\hline & Wool, waste to landfill & $\mathrm{kg}$ & 36.4 & \pm 33 \\
\hline & Sludge, waste to compost or landfill & $\mathrm{kg}$ & 600.5 & \pm 21 \\
\hline & Other non-wool derived waste to landfill & $\mathrm{kg}$ & 43.1 & \pm 46 \\
\hline
\end{tabular}

${ }^{\text {a }}$ An inventory of chemicals used during the processing stages is included in the supplementary material

${ }^{\mathrm{b}}$ This refers to wool with short fibres, which is processed in the woollen processing system

including reuse, respectively) and these values were modelled to determine the difference in usage between genders. Additionally, for comparison, we modelled impacts with the maximum reported garment wear life in the survey data which was 400 wears.

Washing and drying Consumer garment care and other use phase inventory processes were determined from primary data and consumer surveys, reviewed by Laitala et al. (2018) and others (detailed in Table 3). A value of 5.2 days wear per washing event for the garment was taken from the consumer survey data.

Washing was assumed to be done in one of three ways; machine washing, handwashing, or dry cleaning. The proportion of each washing method was taken from the consumer survey data. The size of a washing machine load for wool was taken from a Norwegian study and was $1.6 \mathrm{~kg}$ per wash cycle, which was lower than the typical washing machine load rating for other fibres of $2.3-3.7 \mathrm{~kg}$ per wash cycle (Laitala and Vereide, 2010). The volume of water and electricity required per wool specific program in a washing machine was taken from the same study (Laitala and Vereide, 2010). German consumer survey data indicated that wool is typically washed in a $30{ }^{\circ} \mathrm{C}$ washing machine program and matched the findings of the Norwegian study (Presutto et al., 2007; Kruschwitz et al., 2014). The energy required for dry cleaning using perchloroethylene, the most commonly utilised solvent, was $0.59 \mathrm{kWh}$ per $\mathrm{kg}$ (Troynikov et al., 2016). The ecoinvent European (excl. Switzerland) lowvoltage electricity supply process was applied for all electricity consumption during the use phase, and water for garment washing was modelled with the ecoinvent European (excl. Switzerland) tap water process. Energy consumption in handwashing was calculated using the specific heat capacity of water and assuming two woollen sweaters were washed at a time. It was assumed that 81 of heated water was required (i.e. equivalent to the size of a washing bowl) and that the remaining rinsing water was unheated. The mass of detergent per kilogramme of wool washed by hand was assumed to be equivalent to the amount required for machine washing. Water 
Table 3 Inputs, flows, and outputs associated with woollen garment use and end-of-life disposal by European consumers

\begin{tabular}{|c|c|c|c|}
\hline Parameter & Unit & Amount & Reference \\
\hline \multicolumn{4}{|l|}{ Washing } \\
\hline Washed, machine & $\%$ & 63.0 & Survey data ${ }^{a}$ \\
\hline Washed, hand & $\%$ & 27.5 & Survey data \\
\hline Washed, dry clean & $\%$ & 9.6 & Survey data \\
\hline Washing machine load, wool & $\mathrm{kg}$ & 1.6 & Laitala and Vereide (2010) \\
\hline Water per machine load & 1 & 46.0 & Laitala and Vereide (2010) \\
\hline Water, handwash per kg washed & 1 & 12.8 & Survey data \\
\hline Liquid detergent, per kg washed & $\mathrm{kg}$ & 0.025 & Laitala et al. (2018) \\
\hline Energy, machine wash & $\mathrm{kWh} / \mathrm{kg}$ & 0.19 & Laitala and Vereide (2010) \\
\hline Energy, hand wash & $\mathrm{kWh} / \mathrm{kg}$ & 0.26 & Derived from Energy Saving Trust (2013) \\
\hline Energy, dry cleaning & $\mathrm{kWh} / \mathrm{kg}$ & 0.59 & Troynikov et al. (2016) \\
\hline \multicolumn{4}{|l|}{ Drying } \\
\hline Dried, heated house & $\%$ & 41.1 & Derived from Laitala et al. (2018) \\
\hline Dried, unheated house & $\%$ & 14.9 & Derived from Laitala et al. (2018) \\
\hline Dried, line & $\%$ & 44.0 & Derived from Laitala et al. (2018) \\
\hline Energy, drying heated house & $\mathrm{kWh} / \mathrm{kg}$ & 0.34 & Laitala et al. (2018) \\
\hline \multicolumn{4}{|l|}{ Use and end of Life } \\
\hline Lifetime wear events & Wears & 109.0 & Survey data \\
\hline Wears per year & Wears/year & 14.8 & Survey data \\
\hline Days wear per wash & days & 5.2 & Survey data \\
\hline End of life, recycling & $\%$ & 28.5 & Survey data \\
\hline End of life, municipal waste & $\%$ & 71.5 & Survey data \\
\hline
\end{tabular}

${ }^{\mathrm{a}}$ See primary data in supplementary materials

consumption related to garment washing was determined from water losses, including the fraction lost during garment drying and the fraction lost from wastewater treatment systems. Wastewater from domestic garment washing was modelled using ecoinvent European municipal wastewater treatment processes.

Drying practices for woollen garments were reviewed by Laitala et al. (2018) and the proportion of each is shown in Table 3. The use of tumble drying was assumed to be zero as this practice is uncommon for woollen garments. However, because tumble drying is known to be energyintensive, a sensitivity analysis was used to test the significance of this assumption. The energy required for drying clothes in a heated house was derived from average consumer data of 10 European countries ( $n=2290$ households) with values from Schmitz and Stamminger (2014). It was assumed that the sweater was not ironed, and fabric softeners were not used.

\subsubsection{End-of-life inventory}

The end-of-life disposal processes were determined using woollen sweater-specific data from the consumer survey which provided values of $28.5 \%$ to recycling and $71.5 \%$ to disposal. This reflects the final disposal route after the first or subsequent uses, i.e. after reuse has been accounted for in the total life wears of the garment. The ecoinvent European (excl. Switzerland) municipal waste process was used for the disposal component; this process includes disposal by incineration and landfill, reflective of each European country's waste disposal method.

\subsection{Handling co-production}

Allocation between wool and live weight on sheep farms was handled using biophysical allocation based on protein mass after Wiedemann et al. (2015), and biophysical allocation processes were favoured throughout the supply chain. Economic allocation was not used because this has a lower preference in the allocation hierarchy (ISO, 2006).

Allocation between wool and wool grease (separated during scouring) was handled using mass allocation (92\% allocated to wool) as an approximation of a biophysical method. Wool grease is an important raw material product with many uses, including high-value pharmaceuticals and cosmetics when refined into lanolin.

During processing, wool fibre is separated into multiple flows that are diverted into different processing systems 
(Swan, 2010). The flows between processing systems were handled as mass flows and impacts were partitioned accordingly on the basis of fibre mass. Net fibre mass loss (waste) was reported to be $2-3 \%$ by Swan (2010) and was determined to be in this same order in the present study. This was assumed to be disposed of via municipal waste treatment routes.

The proportion of woollen sweaters recycled may follow either closed or open loop recycling pathways (Russell et al., 2016). There is a long-standing practice of recycling wool, and there is a specific requirement for wool in some products, e.g. mattress padding and automobile acoustic insulation, due to wool's inherent flame resistance and insulation attributes. This ensures demand for recycled wool which results in the fibre maintaining a moderate value $(30 \mathrm{p} / \mathrm{kg}$ - equivalent to AUD $\$ 0.50$, or around $5 \%$ of the value of greasy fibre) (Russell et al., 2016). For the present study, there was no allocation of upstream impacts to raw materials used as inputs to recycling, though further research is needed on this.

\subsection{Analysis}

Modelling was conducted using SimaPro 9.0 (PréConsultants, 2019). Uncertainty was assessed by means of a Monte Carlo analysis in SimaPro, using one thousand iterations to provide a $95 \%$ confidence interval for the results. Normally distributed uncertainty values at two standard deviations from the mean were included for sensitive parameters throughout the value chain. The parameters impacting the length of active garment life were excluded from this analysis and were assessed in the sensitivity analysis. Results were presented using the mean and a $95 \%$ confidence interval.

\section{Results}

\subsection{Impacts}

Environmental impacts per wear were $0.17( \pm 0.02) \mathrm{kg} \mathrm{CO}_{2}$-e GHG, $0.88( \pm 0.18)$ MJ fossil energy, and $0.96( \pm 0.42) \mathrm{L}$ $\mathrm{H}_{2} \mathrm{O}$-e water stress (Fig. 2). Land occupation was also calculated from an inventory throughout the value chain, resulting in $0.32( \pm 0.06) \mathrm{m}^{2}$ per garment wear.

Contributions from different stages of the value chain followed a different pattern depending on the impact category. Greenhouse gas emissions were highest from wool production with lower emissions from processing and retail and garment care. The impacts per gas were $53.7 \%$ for methane (predominantly from wool production), $40.6 \%$ for carbon dioxide (associated with fossil fuel use), and $5.7 \%$ from nitrous oxide (associated with manure and fertiliser volatilisation and fossil fuel use). In wool production, emissions were dominated by enteric methane emitted as a by-product of ruminant digestion in sheep, while in the later stages of the value chain emissions were predominantly related to fossil fuel energy use. Enteric methane emissions are a unique feature of livestock fibre production systems and result in a substantially different emission profile to other natural and synthetic fibres. Considering the high contribution of methane, a sensitivity analysis was performed using the alternative GTP method in the following section.

In contrast to GHG emissions, fossil fuel use was low in the wool production phase and was much higher in the processing phase and the retail and garment care phase. Fibre and fabric processing are mechanical processes driven primarily by electricity and energy for heat (steam) production, which contributed the highest requirement for fossil energy in the value chain. Similarly, garment washing and drying in the garment use phase were found to be energy-intensive, accounting for the high energy requirement from this stage.

With respect to water stress, impacts were spread more evenly between wool production, processing, and garment care. Water stress hotspots related to both the volume of water consumption and the relative water stress. Water consumption and water stress were both below the global average in Europe where garment use occurred (average WSI, 0.357), though it should be noted that WSI varies widely between regions in Europe. In contrast, water consumption was high for wool production, as a proportion of total supply chain impacts (see Fig. 3, see also Figure S1), but WSI values were lower than the global average in the grazing regions where wool is predominantly produced (WSI of 0.214 and 0.012 for NSW and WA respectively), which reduces its impacts. With respect to wool processing, WSI values were high (average WSI, 0.626) but water consumption was moderate because a reasonably high proportion of water is released back to rivers. However, it should be noted that changes in water were not accounted for in this study.

Regarding the freshwater consumption inventory, livestock drinking water and associated supply losses at the farm stage were found to be the most significant contributor (see Fig. 3), with much smaller proportions of water use from processing and garment care. It was noted that water consumption primarily comes from evaporation in the processing stages and during garment care. Water consumption from evaporation was in many instances lower than the total volume of water used in a process, because water was treated and released.

\subsection{Sensitivity analysis}

At the production stage, the model included two broadly different wool production regions with different climate and production systems. Globally, many different production systems are used to produce wool, potentially resulting in different impacts. The sensitivity of the proportions of wool from each region was checked by running the model with $100 \%$ NSW and $100 \%$ WA greasy wool sequentially. The $100 \%$ NSW 
Fig. 2 Greenhouse gas emissions, fossil energy demand, and water stress from the production, use, and end-of-life of a woollen sweater, reported per wear of garment use
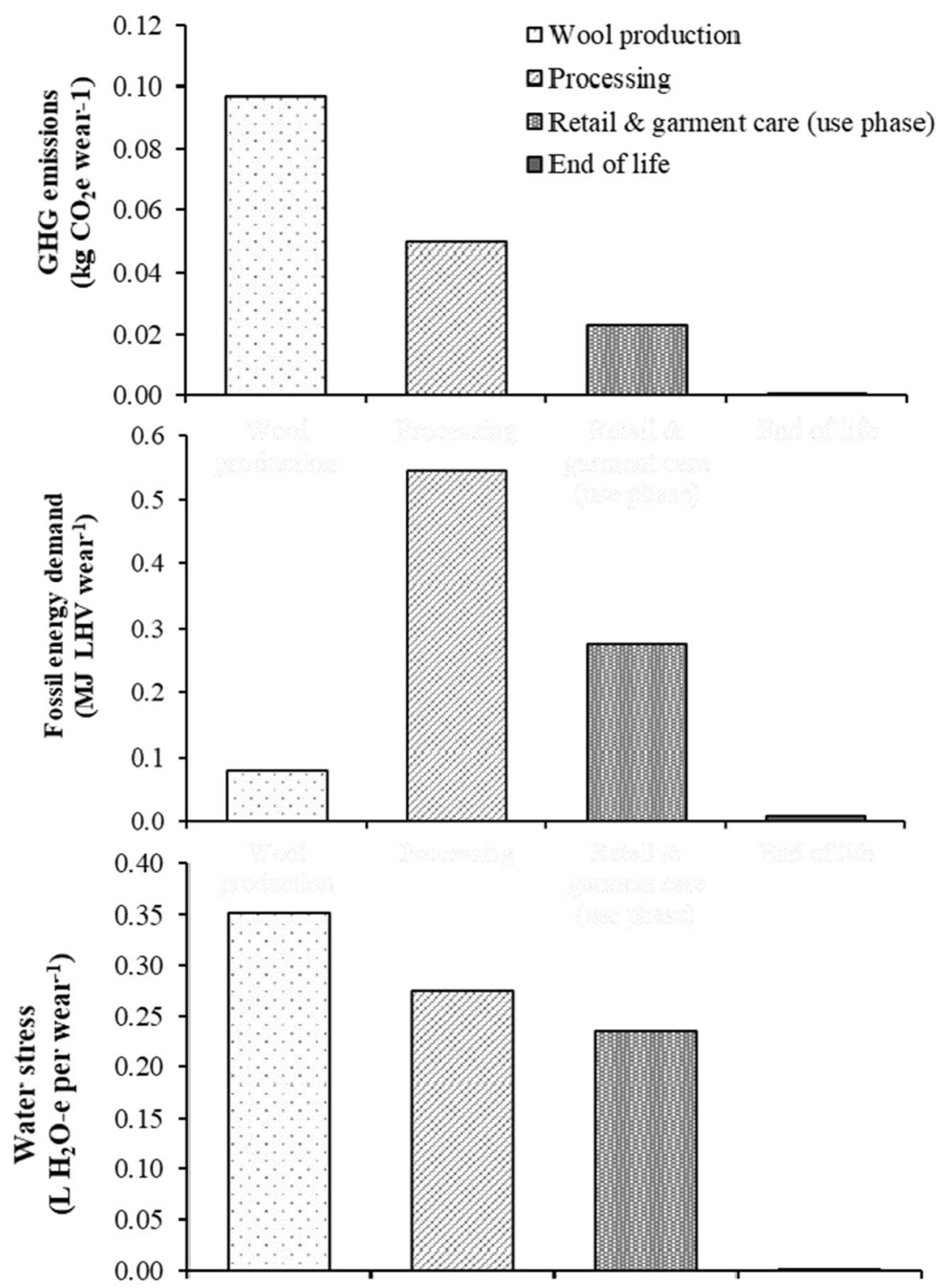

greasy wool increased the cradle-to-grave GHG impacts by $2.9 \%$ and water stress by $24.9 \%$, while fossil fuel use decreased by $0.1 \%$. The $100 \%$ WA greasy wool gave the same value changes, but of opposite sign. These results suggest that region is less sensitive than may be expected for indicators other than water stress, noting that the analysis was limited to only two production regions in Australia. Considering the high contribution of methane to global warming, a sensitivity analysis was performed using GTP, which showed $47.4 \%$ lower impacts than determined using GWP.

With respect to the impact of different levels of garment use, using the data for female consumers from the consumer survey increased cradle-to-grave impacts; GHG increased by $19.9 \%$, fossil fuel by $22.7 \%$, and water stress by $29.2 \%$. Using the data for male consumers from the consumer survey decreased the cradle-to-grave impacts; it reduced GHG by $15.9 \%$, fossil fuel by $17.1 \%$, and water stress by $20.2 \%$. Interestingly, when female and male garments were modelled with different garment mass $(0.25 \mathrm{~kg}$ for females and $0.35 \mathrm{~kg}$ for males to account for size differences), the overall environmental results were similar to the average results. The scenario with maximum reported wears of woollen sweaters of 400 wears, reduced impacts of GHG by $67.5 \%$, fossil fuel by $61.3 \%$, and water stress by $49.4 \%$. Doubling the frequency at which the garment was washed from 5.2 days wear per wash to 2.6 increased impacts of GHG by $7.2 \%$, fossil fuel by $17.1 \%$, and water stress by $32.2 \%$. The use of $100 \%$ tumble drying as an alternative to line and house drying increased impacts of GHG by $3.3 \%$, fossil fuel by $7.6 \%$, and water stress by $2.9 \%$. 
Fig. 3 Contribution analysis for the inventory indicators of freshwater consumption and land occupation, reported per garment wear across the wool value chain

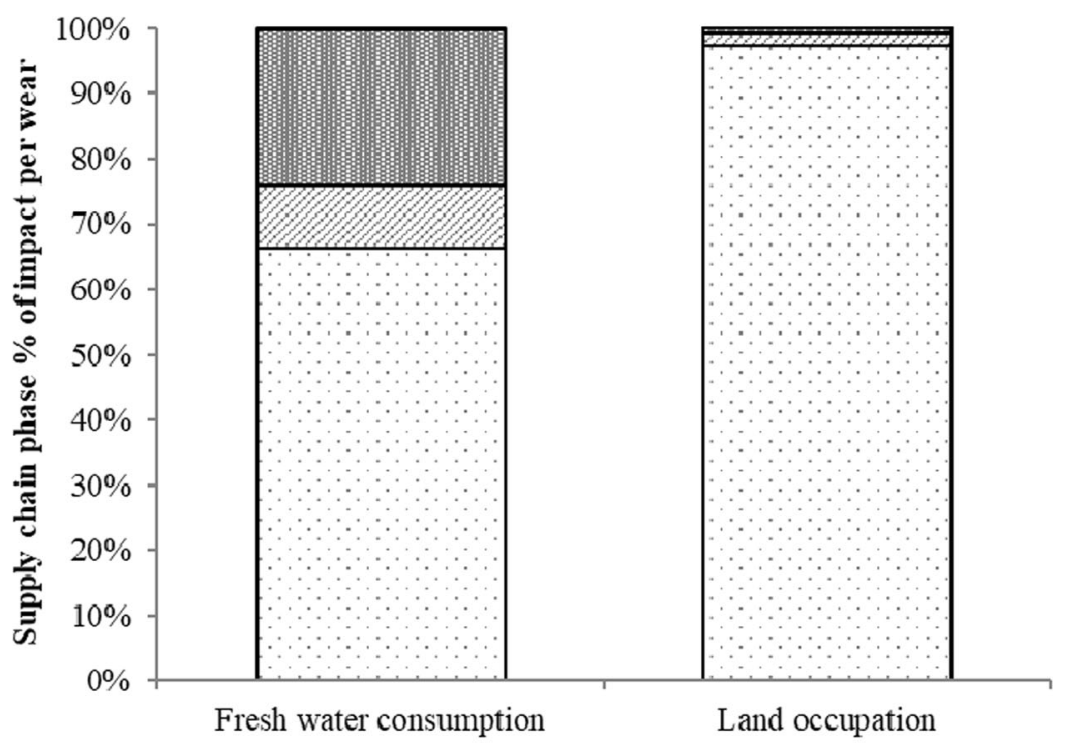

口Wool production aProcessing $\quad$ 口Retail \& garment care (use phase)
Uncertainty analysis results for the impact categories of GHG, fossil fuel, and water stress have been provided in the supplementary materials (Figure S2).

\section{Discussion}

Garment lifetime was the most influential factor determining the impact of woollen garments. In the present study, the total number of wears was estimated to be 109 , based on survey data for woollen sweaters and estimated values for garment reuse. However, if this garment was disposed of after only one season (i.e. 15 uses), this would result in a 5.8- to 6.8-fold increase in environmental impacts and resource use (see Table S13), because raw material production and garment manufacturing impacts were amortised over a shorter period of time, corresponding to fewer wears. Similarly, if a garment was disposed of without reuse by a second user, environmental impacts increase. Conversely, increasing garment lifetime (provided the garment remains in active use) reduced environmental impacts. The survey completed for this study showed that woollen sweaters in consumer wardrobes had been purchased between intervals of $<1$ year and up to $>30$ years ago, and some survey respondents reported garments had been used for $>200$ times and were expected to be used for a further 200 or more times. Increasing the total number of wears to 400 reduced environmental impacts by $49-68 \%$, indicating that substantial improvements are possible via extending garment lifetime, though the maximum number of wears will be limited ultimately by the technical life span of the garment. Considering the importance and variability in garment use, it is clear that the impacts of the use phase must be taken into account to fully understand the environmental impacts of a garment.

Notwithstanding the importance of garment lifetime, it is also important for the supply chain to reduce environmental impacts, and opportunities for efficiency improvements in the main hotspot areas are discussed in the following section.

\subsection{Resource use efficiency in production and processing}

\subsubsection{Environmental efficiency in wool production}

Greenhouse gas mitigation Sheep are ruminants and produce enteric methane emissions as a by-product of digestion. Enteric methane emissions from sheep production accounted for $48.1 \%$ of the total value chain GHG impacts in the current study when $\mathrm{GWP}_{100}$ values were applied, though the significance of methane diminished when the newer GTP method was applied. GTP is an end-point metric at a given point in time and is relevant if looking at an improvement in impacts by a target date, while GWP is arguably more relevant when looking at the overall impacts over a given period. The variability between methods highlights a degree of uncertainty in the approach used for interpreting methane emissions, and the GWP* method of Allen et al. (2016) applied by Cain et al. (2019) should be investigated further. Nonetheless, mitigation of methane is an effective way to reduce short-term impacts from wool production, and mitigation strategies have been examined by Cottle et al. (2011) that show a range of opportunities for reducing these emissions. However, technical and practical barriers exist to their widespread application by the wool industry and further investment in research and technology development is required to improve their 
mitigation potential. Wiedemann et al. (2016) state that sheep production can also sequester carbon in soil and vegetation and their results (from Australian case studies) suggest this could reduce the emissions over the whole life cycle by $4 \%$ for each successive wool production year over a 100 -year period. Shorter term impacts showed more substantial opportunities, and other studies have demonstrated that Australian grazing farms may achieve carbon neutrality for time periods exceeding 30 years (i.e. Doran-Browne et al., 2016). This area warrants further investigation to understand the scale of the opportunity for reducing impacts of wool production. Considering the high contribution of the impacts from this stage, further investigation of the contribution of methane and methane mitigation is warranted.

Water efficiency This study showed that wool production was a hotspot for water consumption and water stress in the wool supply chain. Water consumption in the production phase was elevated because losses from the supply of drinking water for livestock were relatively high, which was associated with the use of small, on-farm water storages (dams) which can have high losses from evaporation (see Wiedemann et al., 2016). Reducing losses through increased use of groundwater and improving the supply efficiency of dams could substantially reduce farm water use.

Land occupation and stocking rates Land occupation was dominated by sheep farming. Australian sheep production systems have relatively low stocking rates (i.e. the number of livestock per hectare) compared with northern hemisphere countries or other wool-producing nations such as New Zealand (Payen and Ledgard, 2017), predominantly because of the lower rainfall and therefore low pasture production in Australia. In contrast to energy or water consumption, the relationship between grazing land occupation and sustainability is not direct. Poorer outcomes can result from 'reduced' land occupation where this is achieved with higher stocking rates, because this can result in land degradation and loss of biodiversity (Ash et al., 1997). Considering this, the present inventory values for wool should not be used to imply environmental impacts and would not be suitable for comparing with other fibres that require cultivated land, such as cotton or hemp.

\subsubsection{Environmental efficiency in wool processing}

Environmental efficiency in wool processing is mainly driven by increasing energy and water efficiency as well as through the reduction of waste. GHG and fossil fuel use impacts are high during the wool processing phase, which accounted for $23.5 \%$ of GHG and $47.7 \%$ of fossil fuel use across the whole wool value chain. Most of the emissions were from Chinese electricity and steam use. There was a high level of variability in electricity and steam use from the processors surveyed, indicating possible efficiency improvements.

In addition to reducing energy use, the change to renewable energy sources provides another opportunity to reduce the GHG emissions related to wool processing. Organic waste from wastewater treatment during the scouring processes could be used to generate renewable energy, which could be used in processing to reduce dependency on fossil fuels. In addition, there are opportunities to increase water efficiency by developing closed-loop systems for water recycling during processing.

Fibre use efficiency Net fibre use efficiency, in an apparel textile context, properly reflects the relative conversion rate of fibre inputs (e.g. clean scoured wool) into the final FU (the finished knitted garment) after accounting for unrecovered (non-recycled) losses of fibre through the conversion process. Where salvage and recycling of wastes are not addressed in estimating fibre wastes (e.g. Smith and Barker, 1995), the resulting gross efficiencies do not reflect a realistic system mass balance, since recovered fibre wastes are economic coproducts which should be included in a LCA assessment. In this cradle to grave study, as is real-world practice, it was assumed that fibre not suitable for the worsted system was diverted to the woollen processing system, which utilises short virgin and diverted wool fibres. Economic incentives for these practices are important and revolve around the comparative high value of wool fibre relative to commodity textile fibres (Russell, et al., 2016) and the cost of diverting textile waste to landfill (Adler and Johnson, 2017).

\subsection{Retail, garment care, and end-of-life disposal}

\subsubsection{Environmental efficiency in garment care}

This study found that the retail and garment use phase was a significant contributor to fossil fuel (30.4\%), global warming $(13.4 \%)$, and water stress (37.1\%). Consumer transport and the retail of garments in stores contributed $12.6 \%$ fossil fuel, $5.2 \%$ global warming, and $3.6 \%$ water stress impacts across the value chain. Similarly, several other garment LCA studies have found the retail and garment care phase was a significant contributor to the total environmental impacts of garments (Cotton Incorporated, 2012, Steinberger et al., 2009, Smith and Barker, 1995, Allwood et al., 2006, Levi Strauss \& Co, 2015). Further investigation to quantify the number of wearing events, especially in subsequent use phases, would be beneficial to improve this aspect of the analysis. Opportunities exist to improve the efficiency of garment care by changing washing and drying practices and via improvements in washing machine efficiency. Washing and drying frequency had a significant bearing on overall impacts. Wool has been shown to inhibit odour (Johnson et al., 2003; Laing, 2019) and therefore may require less washing than 
other fibre types. Airing woollen garments can also reduce odour and reduce the requirement for washing (Laitala et al., 2017). Opportunities also exist to reduce the use of a full machine wash by 'spot-washing' garments as required. Additionally, improved environmental efficiency could be realised by improving the efficiency of washing machines to reduce water use. With respect to drying, line drying of woollen garments without heating also minimises energy requirements. These important considerations require further investigation to quantify best-practice care options for woollen garments, in order to reduce environmental impacts.

\subsubsection{Environmental efficiency via extended garment use and improved end-of-life processes}

Extending garment life spans offers the highest potential for environmental gains. However, because of the importance of garment reuse, this depends on the efficiency of the reuse value chain. For example, private exchange locally may be more efficient than long global chains that require collection points, long transport, and several sorting and resale stages (Farrant, 2008; Fisher, James and Maddox, 2011). However, a thorough comparison should consider whether garment utilisation is improved in trans-national value chains because of improved alignment between garment types and user requirements. Further research is required to understand these factors.

This study assumed that reuse extends the life of the garment, reducing impacts per wear across the total lifespan. Minor impacts were included for collecting, sorting, and transporting clothing for reuse. Following the waste hierarchy, material recycling is the next best option and is realistic for wool because mechanically recycled fibres have value although they are usually downcycled (Russell et al., 2016). In the present study, there was no transfer of environmental impacts between the primary product system and the recycling system, following the PAS 2050 recycled content methodology (BSI, 2011). However, alternative approaches could be applied and this is an area that requires further research. Opportunities also exist to improve the efficiency of disposal, by increasing the utilisation of incineration processes rather than landfill.

\subsection{Limitations and data gaps}

\section{Expanding the knowledge base for wool processes and prod-} ucts Further research is required to determine the impacts of producing wool in other regions including South Africa, New Zealand, South America, Europe, and North America. Different woollen garments also utilise finer or coarser wool types which are bred from different sheep and processed with slightly different methods, requiring further investigation. Specifically, LCA research of woven products (i.e. suits, pants), heavy sweaters, and socks that are made from wool processed within the woollen system would be beneficial.
While this study focused on four main impact areas, other impacts of relevance for wool production, processing, and use exist. Therefore, expanding the study to include impacts on water quality (eutrophication and eco-toxicity), land (including biodiversity), air quality, and human health would be beneficial and relevant.

There were water discharges from the system during processing and garment care where the output quality was not quantified. This reduced water consumption within the value chain by 0.381 per wear for wool processing and 0.701 per wear for garment care. Both discharges were after wastewater treatment and it was assumed the discharges would be within local emissions limits. However, further research is required to determine the impacts on eutrophication and eco-toxicity.

Expanding the knowledge base regarding the use phase This study highlighted the importance of impacts arising from the garment use phase. Further investigation is warranted to determine if the length of garment use and use frequency (a critical factor in the present study) is consistent between different countries and classes of consumer. In addition, further research is required on how to promote an increase in active garment use. Research into new, objective ways to record garment use (wearing frequency and years of garment use) and rates of reuse and disuse would provide higher resolution in this area, as would improve data regarding the utilisation of garments by second and subsequent users. Other methods of assessing garment use include asking about years of garment use and calculating use based on the number of days per year a garment is worn and the quantity of this type of garment owned, similar to the approach used by Roos et al. (2015). This could be a lower cost approach. Research is also required to quantify the frequency and impacts of the wool recycling processes, and this aspect is currently being investigated by members of the authorship. Similarly, washing and drying habits require further investigation. Currently, our research in this area has focused on consumer surveys which often have resulted in limited datasets because of the high cost of surveying, introducing limitations around the representativeness of results. For example, the current study relied on consumer data from only two countries, the UK and Germany, to represent the EU market.

\section{Conclusions}

Wool garments are produced by a complex global supply chain, but to date, studies reported in the literature have focused on only raw material production and/or garment manufacturing, leaving the knowledge base incomplete. The results presented here provide one of the first detailed analyses of the full life cycle of a woollen garment enabling further investigation of efficiency opportunities, and importantly the assessment of the impact of the garment use phase and consumer choices related to garment lifetime. 
Important hotspots were identified at all stages of the system, from production to garment use. Within the production and processing segments of the supply chain, improving production efficiency to reduce resource use and impacts offers opportunities to reduce environmental impacts. With respect to global warming, this study showed that impacts from methane were significant, and changing the reporting metrics from GWP to GTP reduced reported global warming by $47 \%$. These metrics provide different perspectives for supply chains that have high methane emissions, such as wool, and further investigation is required to improve the understanding of woollen supply chains with respect to the contribution to global temperature targets. Garment users were found to have a significant role in determining the period of time that garments remain in active use, which is the most influential factor governing environmental impacts from woollen garments. This highlights the key importance of assessing the full value chain when determining impacts from garments, as partial analyses that include only production and/or processing will not accurately account for important differences in garment use. Considering the significant impact of garment lifetime, large opportunities exist to improve environmental outcomes by extending the active lifetime of garment use by consumers.

Acknowledgements The authors gratefully acknowledge the International Wool and Textiles Organisation (IWTO) for coordinating this research. Industry experts Roy Kettlewell and Rajesh Bahl are acknowledged for their assistance and input with the collection and analysis of textile factory data. Dr. Stewart Ledgard of AgResearch Limited and Angus Ireland of AWI are also acknowledged for their review and input to drafts of this manuscript, as are the anonymous reviewers who provided constructive input to the manuscript during the review.

Funding information This research is funded by Australian Wool Innovation Limited (AWI) which receives matching R\&D funding from the Australian Government.

Open Access This article is licensed under a Creative Commons Attribution 4.0 International License, which permits use, sharing, adaptation, distribution and reproduction in any medium or format, as long as you give appropriate credit to the original author(s) and the source, provide a link to the Creative Commons licence, and indicate if changes were made. The images or other third party material in this article are included in the article's Creative Commons licence, unless indicated otherwise in a credit line to the material. If material is not included in the article's Creative Commons licence and your intended use is not permitted by statutory regulation or exceeds the permitted use, you will need to obtain permission directly from the copyright holder. To view a copy of this licence, visit http://creativecommons.org/licenses/by/4.0/.

\section{References}

Adler M, Johnson A (2017) Let's talk: textile waste. Resource Recycling Systems (RRS), Ann Arbor https://recycle.com/textile-recycling/. Accessed 1 May 2019

ALCAS (2017) AusLCI. Australian Life Cycle Assessment Society (ALCAS), Australia http://auslci.com.au/. Accessed 1 May 2019
Allen MR, Fuglestvedt JS, Shine KP, Reisinger A, Pierrehumbert RT, Forster PM (2016) New use of global warming potentials to compare cumulative and short-lived climate pollutants. Nat Clim Chang 6(8):773-776

Allwood JM, Laursen SE, de Rodriguez CM, Bocken NM (2006) Well dressed. The present and future sustainability of clothing and textiles in the United Kingdom, 1st edn. University of Cambridge Press, Cambridge

Ash A, McIvor J, Mott J, Andrew M (1997) Building grass castles: integrating ecology and Management of Australia's tropical tallgrass rangelands. Rangel J 19(2):123-144

AWEX (2013) AWEX wool pack quality management program, standard no. 3, standards and test methods for woven wool packs made from multifilament nylon yarns. Australian, Wool Exchange Limited (AWEX) http://www.polesy.com.au/assets/Uploads/ AWEX-Wool-Pack-QMPStandar-No.2.pdf. Accessed 1 May 2019

AWEX 2014. Boardtalk. Australian Wool Exchange Limited (AWEX) http://www.awex.com.au/media/1430/boardtalk-november-2014.pdf. Accessed 1 May 2019

Bayart J, Bulle C, Deschênes L, Margni M, Pfister S, Vince F, Koehler A (2010) A framework for assessing off-stream freshwater use in LCA. Int J Life Cycle Ass 15(5):439-453

Brent AC, Hietkamp S (2003) Comparative evaluation of life cycle impact assessment methods with a South African case study. Int J Life Cycle Ass 8(1):27

Brock PM, Graham P, Madden P, Alcock DJ (2013) Greenhouse gas emissions profile for $1 \mathrm{~kg}$ of wool produced in the Yass region, New South Wales: a life cycle assessment approach. Anim Prod Sci 53(6):495-508

BSI (2011) PAS 2050: specification for the assessment of the life cycle greenhouse gas emissions of goods and services. Department for Business Innovation \& Skills, UK http://shop.bsigroup.com/ upload/shop/download/pas/pas2050.pdf. Accessed 1 May 2019

Cain M, Lynch J, Allen MR, Fuglestvedt JS, Frame DJ, Macey AH (2019) Improved calculation of warming-equivalent emissions for short-lived climate pollutants. NPJ Clim Atmos Sci 2(1):1-7

CIBSE (2012) Benchmarks. In: Cheshire D (ed) GVF 2012 guide F: energy efficiency in buildings. chartered institution of building service engineers (CIBSE), England

Claudio L (2007) Waste couture: environmental impact of the clothing industry. Environ Health Perspect 115(9):A449-A454. https://doi. org/10.1289/ehp.115-a449. Accessed 1 May 2019

Commonwealth of Australia (2018) National Inventory Report (NIR) 2016, vol 1. Australian Government, Department of the Environment and Energy (DEE), Australia

Cottle D, Nolan J, Wiedemann S (2011) Ruminant enteric methane mitigation: a review. Anim Prod Sci 51(6):491-514

Cotton Incorporated (2012) Life cycle assessment of cotton fiber \& fabric: full report. Cotton Incorporated, America

Doran-Browne NA, Ive J, Graham P, Eckard RJ (2016) Carbon-neutral wool farming in South-Eastern Australia. Anim Prod Sci 56(3):417-422

EC-JRC (2010) I LCD handbook: International Reference Life Cycle Data System. General Guide for Life Cycle Assessment - Detailed Guidance. European Commission - Joint Research Centre. Institute for Environment and Sustainability, Ispra https://eplca.jrc.ec.europa. eu/uploads/ILCD-Handbook-General-guide-for-LCA-DETAILEDGUIDANCE-12March2010-ISBN-fin-v1.0-EN.pdf. Accessed 1 May 2019

ecoinvent (2019) ecoinvent LCI database. ecoinvent Centre, Basel https:// www.ecoinvent.org/database/database.html. Accessed 1 May 2019

Energy Saving Trust (2013) At home with water: the biggest ever review of domestic water use in Great Britain. Energy Saving Trust, UK https://energysavingtrust.org.uk/sites/default/files/reports/ AtHomewithWater\%287\%29.pdf. Accessed 1 May 2019

Farrant L (2008) Environmental benefits from recycling clothes. Technical University of Denmark, Lyngby 
Finnveden G, Hauschild MZ, Ekvall T, Guinée J, Heijungs R, Hellweg S, Koehler A, Pennington D, Suh S (2009) Recent developments in life cycle assessment. J Environ Manag 91(1):1-21

Fisher K, James K, Maddox P (2011) Benefits of reuse case study: clothing. Banbury, UK, WRAP

GfK (2012) European retail in 2017 - GfK study on key retail indicators: 2016 review and 2017 forecast, England: growth from knowledge (GfK). Geomarketing (GfK), Germany https://www.eurocommerce. eu/media/141240/GfK\%20-\%20European_Retail_Study_2017.pdf. Accessed 1 May 2019

Henry B, Russell S, Ledgard S, Gollnow S, Wiedemann S, Nebel B, Maslen D, Swan P (2015) LCA of wool textiles and clothing. In: Handbook of life cycle assessment (LCA) of textiles and clothing, 1st edn. Woodhead Publishing, Cambridge, pp 217-254

IPCC (ed) (2013) Climate change 2013: the physical science basis. Contribution of Working Group I to the Fifth Assessment Report of the Intergovernmental Panel on Climate Change. Cambridge University Press, Cambridge

ISO (2006) Environmental Management - life cycle assessment - requirements and guidelines. ISO 14044:2006. International Organisation for Standardisation (ISO), Geneva

ISO (2013) Greenhouse gases - carbon footprint of products - requirements and guidelines for quantification and communication. ISO/TS 14067. International Organisation for Standardisation (ISO), Geneva

ISO (2014) Environmental management - water footprint - principles, requirements and guidelines. ISO 14046:2014. International Organisation for Standardisation (ISO), Geneva

IWTO (2016) Guidelines for conducting a life cycle assessment of the environmental performance of wool textiles. International Wool Textile Organisation (IWTO), Australia

IWTO (2018) IWTO market information edition 13. International Wool Textile Organisation (IWTO), Brussels

Johnson N, Wood E, Ingham P, McNeil S, McFarlane I (2003) Wool as a technical fibre. J Text I 94:26-41

Kruschwitz A, Karle A, Schmitz A, Stamminger R (2014) Consumer laundry practices in Germany. Int J Consum Stud 38(3):265-277

Laing RM (2019) Natural fibres in next-to-skin textiles: current perspectives on human body odour. SN Appl. Sci 1(11):1329

Laitala K, Klepp I, Henry B (2018) Does use matter? Comparison of environmental impacts of clothing based on fiber type. Sustainability 10(7):2524

Laitala K, Klepp IG, Henry B (2017) Global laundering practicesalternatives to machine washing. Household and Personal Care Today https:/oda.hioa.no/en/item/asset/dspace:14930/Global\% 20laundering $\% 20$ practices-submission2_changes_accepted.pdf. Accessed 1 May 2019

Laitala K, Vereide K (2010) Washing machines' program selections and energy use. National Institute for Consumer Research, Oslo

Levi Strauss \& Co. (2015) The life cycle of a jean: understanding the environmental impact of a pair of Levi's 501 jeans. Levi Strauss \& Co, USA https://www.resourceefficient.eu/fr/node/1248. Accessed 1 May 2019

Muthu SS (2014) Assessing the environmental impact of textiles and the clothing supply chain, 1 st edn. Woodhead publishing, Cambridge

Muthu SS (2015) Handbook of life cycle assessment (LCA) of textiles and clothing, 1st edn. Woodhead publishing, Cambridge

NEXT PLC (2015) Results for the year ending January 2015. NEXT, UK http://www.nextplc.co.uk/ /media/Files/N/Next-PLC-V2/documents/ reports-and-presentations/2014/full-year-results-2014.pdf. Accessed 1 May 2019

NREL (2012) U.S. Life Cycle Inventory Database. National Renewable Energy Laboratory (NREL), United States https://www.nrel.gov/ lci/. Accessed 1 May 2019

Payen S, Ledgard SF (2017) Aquatic eutrophication indicators in LCA: methodological challenges illustrated using a case study in New Zealand. J Clean Prod 168:1463-1472
Petrie O (1995) Harvesting of textile animal fibres. Food \& Agriculture Org (FAO), UN, Italy

Pfister S, Koehler A, Hellweg S (2009) Assessing the environmental impacts of freshwater consumption in LCA. Environ Sci Technol 43(11):4098-4104

Presutto, M., Stamminger, R., Scialdoni, R., Mebane, W. and Esposito, R. (2007) Preparatory studies for eco-design requirements of EuPs. LOT 14: domestic washing machines \& dishwashers - final report: ISIS

Pré-Consultants (2019) SimaPro 9.0 Software, Amersfoort, Netherlands: Pré-Consultants

Remy N, Speelman E, Swartz S (2016) Style that's sustainable: a new fastfashion formula. McKinsey \& Company, Sustainability \& Resource Productivity http://www.mckinsey.com/business-functions/ sustainability-and-resource-productivity/our-insights/style-thatssustainable-a-new-fast-fashion-formula. Accessed 1 May 2019

Ridoutt BG, Pfister S (2010) A revised approach to water foot-printing to make transparent the impacts of consumption and production on global freshwater scarcity. Global Environ Chang 20(1):113-120

Roos S, Sandin G, Zamani B, Peters G (2015) Environmental assessment of Swedish fashion consumption. Five garments-sustainable futures, Sweden http://www.mistrafuturefashion.com/wp-content/ uploads/2015/06/Environmental-assessment-of-Swedish-fashionconsumption-LCA.pdf. Accessed 1 May 2019

Russell S, Swan P, Trebowicz M, Ireland A (2016) Review of wool recycling and reuse. In: Fangueiro R, Rana S (eds) Natural Fibres: advances in science and technology towards industrial applications: from science to market, 1st edn. Springer Netherlands, Dordrecht, pp 415-428

SAC (2017) Higg materials sustainability index (MSI) methodology, San Francisco. Sustainable Apparel Coalition (SAC), California

Smith G, Barker R (1995) Life cycle analysis of a polyester garment. Resour Conserv Recycl 14(3-4):233-249

Schmitz A, Stamminger R (2014) Usage behaviour and related energy consumption of European consumers for washing and drying. Energ Effic 7(6):937-954

Steinberger JK, Friot D, Jolliet O, Erkman S (2009) A spatially explicit life cycle inventory of the global textile chain. Int J Life Cycle Ass 14(5):443-455

Swan P (2010) Wool as an apparel fibre. International Sheep and Wool Handbook. Nottingham University Press, Nottingham, p 766

thinkstep (2017) New Zealand merino: transforming the New Zealand wool industry by creating the most innovative, sustainable primary industry possible. thinkstep and the New Zealand Merino Company, New Zealand

Troynikov O, Watson C, Jadhav A, Nawaz N, Kettlewell R (2016) Towards sustainable and safe apparel cleaning methods: a review. J Environ Manag 182:252-264

UN (2019) World population prospects 2019: volume I: comprehensive tables. Department of Economic and Social Affairs, Population Division, United Nations

Wiedemann S, Ledgard S, Henry B, Yan M, Mao N, Russell S (2015) Application of life cycle assessment to sheep production systems: investigating co-production of wool and meat using case studies from major global producers. Int J Life Cycle Ass 20(4):463-476

Wiedemann S, Yan M-J, Henry B, Murphy C (2016) Resource use and greenhouse gas emissions from three wool production regions in Australia. J Clean Prod 122:121-132

Wood E (2010) Wool processing. In: Cottle DJ (ed) International sheep and wool handbook. Nottingham University Press, Nottingham

WRAP (2011) Benefits of reuse case study: clothing. WRAP, Banbury

Publisher's note Springer Nature remains neutral with regard to jurisdictional claims in published maps and institutional affiliations. 